\title{
Troponin T from the Japanese Pearl Oyster Pinctada fucata: Molecular Cloning, Tissue Distribution, Gene Structure, and Interaction Analysis with Tropomyosin
}

\author{
Daisuke Funabara* ${ }^{\circledR}$, Yoshinori Urakawa, Daisuke Ishikawa, Satoshi Kanoh \\ Graduate School of Bioresources, Mie University, Tsu, Japan \\ Email: ${ }^{\star}$ funabara@bio.mie-u.ac.jp
}

How to cite this paper: Funabara, D., Urakawa, Y., Ishikawa, D. and Kanoh, S. (2020) Troponin T from the Japanese Pearl Oyster Pinctada fucata: Molecular Cloning, Tissue Distribution, Gene Structure, and Interaction Analysis with Tropomyosin. American Journal of Molecular Biology, 10, 61-73.

https://doi.org/10.4236/ajmb.2020.101006

Received: November 20, 2019

Accepted: December 17, 2019

Published: December 20, 2019

Copyright $\odot 2020$ by author(s) and Scientific Research Publishing Inc. This work is licensed under the Creative Commons Attribution International License (CC BY 4.0).

http://creativecommons.org/licenses/by/4.0/

\begin{abstract}
Troponin (Tn) is composed of three subunits (TnI, TnC and $\mathrm{TnT}$ ) that bind $\mathrm{Ca}^{2+}$ and regulate striated muscle contraction in vertebrates. TnT's function has been extensively described in vertebrates, but its role has been obscure in molluscan muscles. Our previous work indicated that the $\mathrm{TnC}$ and $\mathrm{TnI}$ subunits work in adductor phasic muscle, but not in catch muscle. Here, we have characterized TnT from the Japanese bivalve pearl oyster Pinctada fucata to start to explain the function of $\mathrm{Tn}$ in molluscan muscle contraction. We determined the primary structure of the full-length TnT protein from the $P$. fucata adductor muscle (Pifuc-TnT), and found that it is composed of 316 amino acid residues with a predicted molecular mass of $37.4 \mathrm{kDa}$. Multiple sequence alignment showed that Pifuc-TnT has an extension of $>60$ residues at the C-terminus that are not present in vertebrate TnTs, including known TnTs from other mollusks. Pifuc-TnT gene structure predictions using Splign alignment of the cDNA generated in this study and genome sequences indicated that Pifuc-TnT consists of 13 exons. Start and stop codons are located in exons 2 and 12, respectively. Quantitative real-time PCR revealed that the Pifuc-TnT gene was predominantly expressed in adductor phasic muscle, weakly in adductor catch muscle, slightly in gill, and not at all in mantle and foot. These findings suggest that TnT plays a regulatory role in adductor phasic muscle contraction, but not in catch contraction. Isothermal titration calorimetry revealed that unlike vertebrate TnTs, Pifuc-TnT does not interact with $P$. fucata tropomyosin-1 nor with tropomyosin-2. These findings in $P$. fucata imply that Tn functions differently in molluscan muscle than it does in vertebrates.
\end{abstract}

\section{Keywords}

Adductor Muscle, Catch Contraction, Pinctada fucata, Troponin T, Tropomyosin 


\section{Introduction}

Bivalve adductor muscles are composed of phasic and catch muscles. The larger phasic muscle is used to close shells quickly and the smaller catch muscle is used to keep shells closed. Catch muscles can maintain their tension for long periods with little energy consumption after developing the contraction [1]. They start to contract following an increase in intracellular $\mathrm{Ca}^{2+}$ concentrations, which activates myosin and creates tension, and then they subsequently enter the catch state once $\mathrm{Ca}^{2+}$ concentrations decrease to resting levels. In the catch state, twitchin-a member of the titin/connectin family-is considered to tether thin and thick filaments together by forming a complex with myosin and actin [2] [3] [4].

Unlike molluscan muscles, a thin filament-linked regulatory system is used by vertebrate striated muscles. Troponin $(\mathrm{Tn})$ is a regulator of skeletal muscle contraction. It is arranged over thin filaments and prevents actin-myosin interaction. Tn consists of three subunits: troponin $\mathrm{C}(\mathrm{TnC})$, troponin I (TnI), and troponin $\mathrm{T}(\mathrm{TnT}) . \mathrm{Ca}^{2+}$ binding to $\mathrm{TnC}$ leads to a conformational change in the complex structure of Tn that allows myosin to interact with actin [5] [6] [7] [8]. While Tn is also present in molluscan muscles, whether it is involved in a thin filament-linked regulatory system similar to that in vertebrates is currently unclear.

The Japanese pearl oyster, Pinctada fucata, is one of the most important molluscan species in the pearl culture industry [9]. Recently, the P. fucata genome database was published in which all major muscle protein genes were annotated [10] [11] [12]. This database allowed $P$. fucata a convenient model system to elucidate the regulatory system of molluscan muscle. To examine the molecular mechanism of thin filament-linked regulation of molluscan muscle contraction, our studies have centered on the adductor muscle Tn subunits. To this end, $P$. fucata TnC (Pifuc-TnC) and TnI (Pifuc-TnI) have recently been described [13] [14] [15]. Pifuc-TnC has four EF-hand motifs, sites I-IV, and, like other molluscan TnCs [16] [17] [18], only site IV is able to bind $\mathrm{Ca}^{2+}$ [12]. In Pifuc-TnC, a conformational change is caused by $\mathrm{Ca}^{2+}$-binding [12]. A potential Pifuc-TnC three-dimensional model closely resembles that of vertebrate $\mathrm{TnC}$, apart from a short loop (four amino acids) in the former structure that splits the $\alpha$-helix, which connects the N- and C-terminal lobes [14]. Quantitative real-time PCR suggested that the Pifuc-TnC gene is predominantly expressed in phasic adductor muscle, indicating a role for $\mathrm{Tn}$ in adductor phasic muscle control [14].

Molluscan TnIs have an extension sequence at their N-terminus that differentiates them from mammalian TnIs [15] [19] [20]. Like other molluscan TnI proteins, Pifuc-TnI has a 138-residue extension at its $\mathrm{N}$-terminus that is not present in rabbit TnI [19] [20]. This extension is rich in the charged amino acids glutamic acid and arginine. Software for predicting motif structures suggests that Pifuc-TnI comprises two coils (4 - 25 and 60 - 152 residues) and a troponin motif (161 - 286 residues). Pifuc-TnI also includes consensus sequences for cAMP-dependent protein kinase in residues 39 - 45 (RRGTEDD) and 145 - 151 (KKKSKRK), which are 
unique from scallop TnIs [15]. A number of different protein kinases in vertebrate cardiac muscle have been shown to phosphorylate TnI [21], increasing the probability that Pifuc-Tn controls the phasic adductor muscle contraction in a similar fashion.

TnT's properties are widely investigated using rabbit skeletal TnT [22]. Rabbit TnT interacts with tropomyosin with a stoichiometry of 1 to 1 . The complex structure includes the interaction between the $\mathrm{TnT}$ and tropomyosin helical regions [23]. There are no reports on the interaction between molluscan $\mathrm{TnT}$ and the TnI-TnC complex. As described above, molluscan TnI and TnC possess distinctively different characteristics from their vertebrate counterparts, implying that complexes of molluscan Tn subunits could form in a different way from those of vertebrates. To contribute to the research on molluscan Tn formation, we determined the molecular characteristics of P. fucata TnT (Pifuc-TnT) in this study.

In our previous study, we revealed that two tropomyosin isoforms, tropomyosin-1 (Pifuc-TM1) and tropomyosin-2 (Pifuc-TM2), are expressed by alternative RNA processing of a single gene and selectively used in phasic and catch muscles [24]. Pifuc-TM1 is expressed in phasic muscle, whereas both Pifuc-TM1 and Pifuc-TM2 are expressed to the same extent in catch muscle [24].

Pifuc-TnC and Pifuc-TnI are predominantly expressed in phasic muscle, suggesting that Pifuc-Tn proteins in phasic muscle operate within a regulatory system [14] [15]. Therefore, we speculated that Pifuc-TnT interacts with Pifuc-TM1 and not Pifuc-TM2. To confirm this, we performed an isothermal titration calorimetric (ITC) analysis to determine whether Pifuc-TnT interacts with Pifuc-TM1 and/or Pifuc-TM2.

\section{Materials and Methods}

\subsection{Pearl Oysters}

Samples were prepared as previously reported [14]. Briefly, we obtained live specimens of 2-year-old Japanese pearl oysters $P$. fucata that were cultured in Ago Bay, Mie Prefecture, Japan. The adductor muscle, gill, mantle and foot were dissected from each oyster body, immediately frozen in liquid nitrogen, and stored at $-80^{\circ} \mathrm{C}$ until use.

\section{2. cDNA Cloning of $P$. fucata Troponin T}

cDNA cloning was carried out as previously reported with some modifications [14]. Briefly, total RNA was extracted from the phasic part of the $P$. fucata adductor muscle using a conventional method [25]. The partial nucleotide sequences of $P$. fucata troponin T (Pifuc-TnT) (accession number AB735598), as determined by 3 rapid amplification of cDNA ends (RACE), have been previously reported [11]. To determine the full-length sequence of Pifuc-TnT, 5' RACE was carried out using the 5 ' RACE System for Rapid Amplification of cDNA Ends, version 2.0 (Invitrogen, Carlsbad, CA, USA) using total RNA as a template. The fol- 
lowing primers were designed using the elucidated sequences of Pifuc-TnT: 5'-CATTAGTCTGAATATGTTCT-3' for synthesizing cDNA; 5'-TGAAGCTCT TTGGCCATTTC-3' for the first PCR, and 5'-CCAGCTTGGCAGTGTCCACT-3' for the second PCR. PCR was carried out using SapphireAmp Fast PCR Master Mix (TaKaRa Bio, Shiga, Japan) with the forward primers detailed above and the reverse primers included in the kit. The PCR conditions were as follows: 30 cycles of denaturation at $98^{\circ} \mathrm{C}$ for $5 \mathrm{~s}$, annealing at $55^{\circ} \mathrm{C}$ for $5 \mathrm{~s}$, and elongation at $72^{\circ} \mathrm{C}$ for $10 \mathrm{~s}$. The nucleotide sequence data determined in this study were registered in the DNA Data Bank of Japan, EMBL and GenBank sequence databases (accession number LC507099).

\subsection{Comparison of the Primary Structure of $P$. fucata TnT with Those from Other Species}

The primary structure of Pifuc-TnT was determined by the nucleotide sequence of Pifuc-TnT. This sequence was compared with TnT amino acid sequences from Japanese scallop, Chlamys nipponensis (D88423), Yesso scallop Mizuhopecten yessoensis (AB004637), human Homo sapiens (S69208), mouse Mus musculus (L49018), zebrafish Danio rerio (AF512524), and Atlantic salmon Salmo salar (AF072687), using Clustal W [26].

\subsection{Gene Structure of $P$. fucata TnT}

BLAST searching the Pifuc-TnT nucleotide sequence against the $P$. fucata genome database yielded the genome sequence including the Pifuc-TnT gene. [10]. The gene structure of the Pifuc-TnT gene was predicted by analyzing cDNA and genome sequences using the Splign alignment tool of the National Center for Biotechnology Information [27].

\subsection{Gene Expression Analysis of $P$. fucata TnT in Tissues}

Gene expression analysis was carried out as previously reported with some modifications [14]. Briefly, gene expression patterns of Pifuc-TnT in catch and phasic muscles, gill, mantle and foot were analyzed by quantitative real-time PCR. The cDNAs were synthesized using total RNA from each tissue as templates using ReverTra Ace ${ }^{\circledR}$ qPCR RT Master Mix (Toyobo Co. Ltd., Osaka, Japan). The primers and a probe were designed by the Universal Probe Library Assay Design Center (Roche Diagnostics, Mannheim, Germany) using the full-length nucleotide sequence determined in this study. The sequences of the primers used to amplify Pifuc-TnT were: 5'-AAGCCACTGACCACTGACG-3' (forward) and 5'-TGAAGCTCTTTGGCCATTTC-3' (reverse); probe \#130 (Roche Diagnostics) was used as a TaqMan probe. $P$. fucata glyceraldehyde 3-phosphate dehydrogenase $(G A P D H)(\mathrm{KX} 129947)$ was used as an internal standard and amplified using the following primer sequences: 5'-CACTGCGGCCTCTAACATC-3' (forward) and 5'-ACTTTGCCTACGGCTTTGG-3' (reverse); probe \#88 (Roche Diagnostics) was used as a TaqMan probe. PCR reactions were performed using Eagle 
Taq Master Mix with ROX (Roche Diagnostics). The PCR conditions were as follows: 40 cycles of denaturation at $95^{\circ} \mathrm{C}$ for $3 \mathrm{~s}$ and annealing and elongation at $60^{\circ} \mathrm{C}$ for $30 \mathrm{~s}$.

\subsection{Protein Preparation}

Pifuc-TnT was prepared as previously reported with some modifications [13]. Briefly, Pifuc-TnT was expressed in Escherichia coli as a histidine-tagged protein. A DNA fragment codon-optimized for expression in $E$. coli and encoding the full length of the open reading frames was commercially synthesized (GenScript, Piscataway, NJ, USA). The plasmid pET15b (Novagen, Darmstadt, Germany) was used to create the expression vector $p E T$-Pifuc-TnT. E. coli BL21 (DE3) cells were transformed with pET-Pifuc-TnT and cultured in auto-induction media at $37^{\circ} \mathrm{C}$ for $24 \mathrm{~h}$ [28]. The cultured E. coli collected by centrifugation were suspended in a lysis buffer included in the EzBactYeast Crusher kit (ATTO, Tokyo, Japan). The insoluble fraction of the lysate containing Pifuc-TnT was obtained by centrifugation as a pellet. The pellet was resuspended in denaturing immobilized metal ion affinity chromatography (IMAC) lysis buffer (6 M urea, $600 \mathrm{mM} \mathrm{KCl}, 100 \mathrm{mM} \mathrm{KH}_{2} \mathrm{PO}_{4}, 10 \mathrm{mM}$ imidazole, $\mathrm{pH} \mathrm{8.0)}$. The supernatant fraction including Pifuc-TnT obtained by centrifugation was subjected to affinity chromatography with a Bio-Scale Mini Profinity IMAC cartridge (Bio-Rad, Hercules, CA, USA) under denaturing conditions according to the manufacturer's instructions. P. fucata tropomyosin-1 (Pifuc-TM1) and -2 (Pifuc-TM2) were prepared as previously reported [24]. Purified proteins were lyophilized after dialysis against $10 \mathrm{mM}$ ammonium bicarbonate ( $\mathrm{pH} 8.0)$.

\subsection{Isothermal Titration Calorimetric Analysis}

The Pifuc-TnT interaction with Pifuc-TM1 was calculated by ITC with a MicroCal iTC200 calorimeter (Malvern Panalytical Ltd., Malvern, UK) as previously reported with some modifications [13]. Lyophilized protein samples were resuspended and dialyzed overnight against $10 \mathrm{mM}$ PIPES-KOH ( $\mathrm{pH} \mathrm{6.8)} \mathrm{con-}$ taining $0.15 \mathrm{M} \mathrm{NaCl}$ and $1 \mathrm{mM} 2$-mercaptoethanol at $4^{\circ} \mathrm{C}$. Pifuc-TnT and Pifuc-TM1 were adjusted to final concentrations of $1.05 \mathrm{mM}$ and $70 \mu \mathrm{M}$, respectively, using the external dialysis buffer. The experimental parameters were as follows: total number of injections, 18 ; cell temperature, $25^{\circ} \mathrm{C}$; reference power, $10 \mu \mathrm{cal} / \mathrm{s}$; syringe concentration, $1.05 \mathrm{mM}$; cell concentration, $70 \mu \mathrm{M}$; and stirring speed, 1,000 rpm. The injection parameters were as follows: volume, $2.0 \mu \mathrm{L}$; and spacing, $200 \mathrm{~s}$. Titration was performed at $25^{\circ} \mathrm{C}$ by injecting $2.0 \mu \mathrm{L}$ of 1.05 $\mathrm{mM}$ Pifuc-TnT into the ITC cell containing $300 \mu \mathrm{L}$ of $70 \mu \mathrm{M}$ Pifuc-TM1. The data thus obtained were corrected for the heat of dilution and analyzed using MicroCal Analysis Launch software (Malvern Panalytical Ltd.). The Pifuc-TnT interaction with Pifuc-TM2 was calculated as described above except that 1.36 $\mathrm{mM}$ Pifuc-TnT was used in the injection syringe and $92 \mu \mathrm{M}$ Pifuc-TM2 was used in the ITC cell. 


\section{Results}

\subsection{Molecular Characteristics of $P$. fucata Troponin T}

The Pifuc-TnT full-length nucleotide sequence was obtained by cDNA cloning with 1704 nucleotides, which contains an open reading frame of 948 nucleotides, a 72-nucleotide 5 ' untranslated region, and a 681-nucleotide 3 ' untranslated region (Figure 1). It encodes a protein of 316 amino acid residues in length with a predicted molecular mass of $37.4 \mathrm{kDa}$ (Figure 1). Comparison of the amino acid sequences between TnT of $P$. fucata and other species showed the following homology: 51\% (Japanese scallop), 52\% (Yesso scallop), 26\% (human), 28\% (mouse), 19\% (zebrafish) and 28\% (Atlantic salmon) (Figure 2). As in the known scallop TnTs, the C-terminal extension of Pifuc-TnT contains $>60$ residues not present in vertebrate TnTs [29].

The BLAST nucleotide sequence search for Pifuc-TnT against the $P$. fucata genome database yielded a gene model (pfu_aug2.0_648.1_27_629.t1) that had been calculated from the genome sequence. The gene model sequence was missing

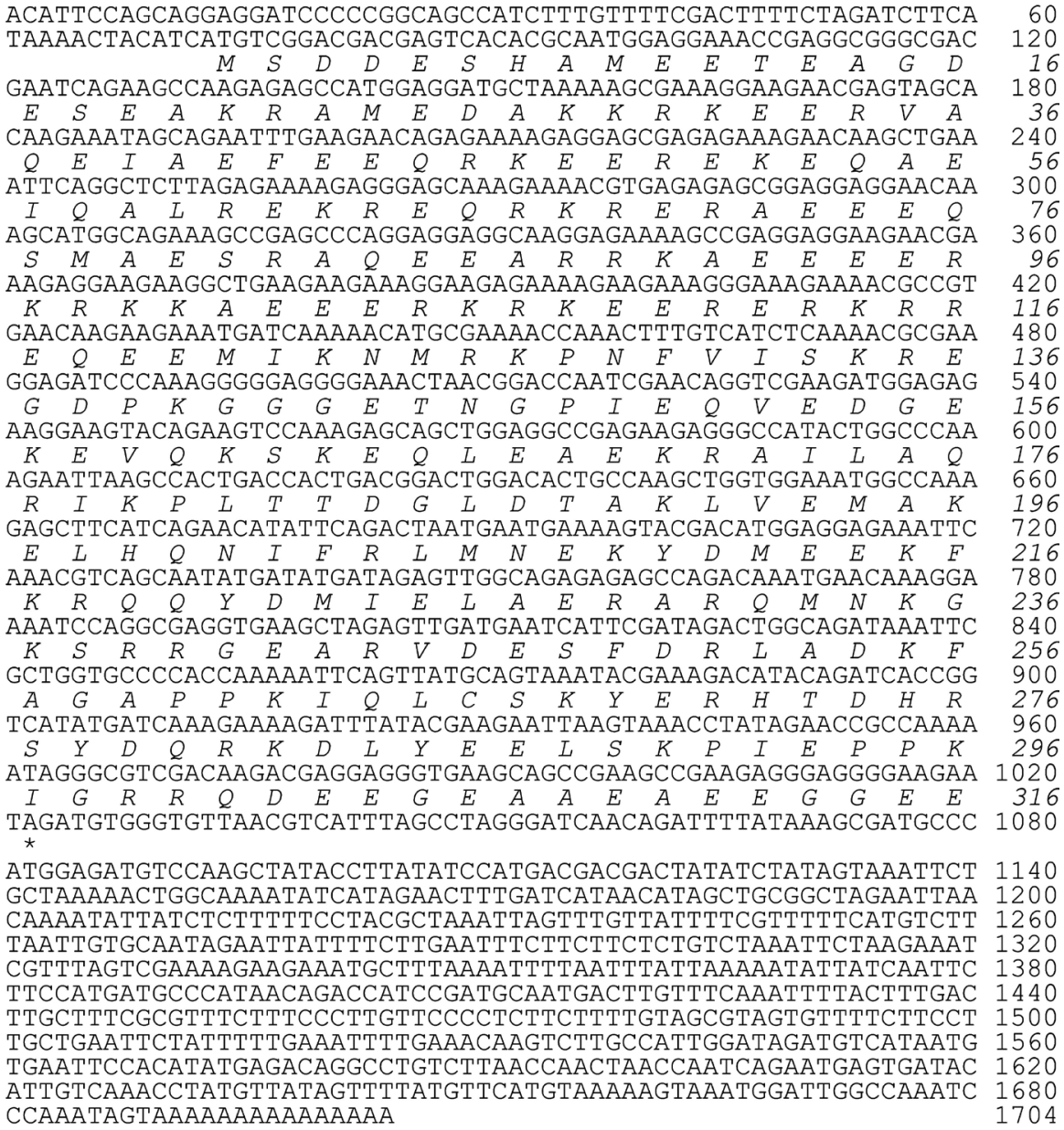

Figure 1. Pinctada fucata troponin T nucleotide and deduced amino acid sequences. The amino acid sequence is represented in italics. Numbers on the right indicate the numbers of nucleotides from the 5 -end and amino acid residues from the $\mathrm{N}$-terminus. The stop codon is indicated by an asterisk. 
Pifuc-TnT

Japanese scallop

Yesso scallop

Human

Mouse

Zebrafish

Atlantic salmon

Pifuc-TnT

Japanese scallop

Human

Mouse

Zebrafish

Atlantic salmon

Pifuc-TnT

Japanese scallop

Yesso scallop

Human

Mouse

Zebrafish

Atlantic salmon

Pifuc-TnT

Japanese scallop

Yesso scallop

Human

Mouse

Zebrafish

Atlantic salmon

Pifuc-TnT

Japanese scallop

Yesso scallop

Human

Mouse

Zebrafish

Atlantic salmon

Pifuc-TnT

Japanese scallop

Yesso scallop

Human

Mouse

Zebrafish

Atlantic salmon

Pifuc-TnT

Japanese scallop

Yesso scallop

Human

Mouse

Zebrafish

Atlantic salmon

Pifuc-TnT

Japanese scallop

Yesso scallop

Human

Mouse

Zebrafish

Atlantic salmon
Yesso scallop

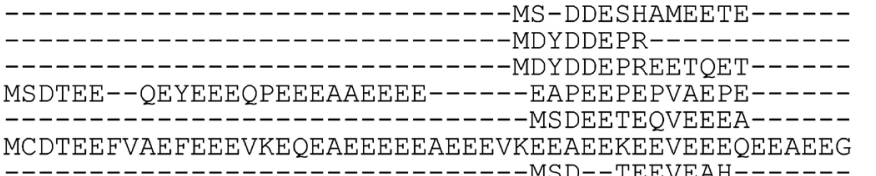

-AGDFSEAKRAMEDAKKRKEERVAOETAEFEEORK

--------------TGDGNEARLAMEEAARKKKEKVESE IAEYEEMRR

-------------TGDGNEARLAMEEAARKKKEKVESEIAEYEEMRR

------OEEEVOEEAPEPEEKPRPKLTAP-----KIPEGEKVDFDDIOK 51 DEPFETHOFFADDE - 32

EEREKEQAEIQALREKREQRKRERAEEEQSMAESRAQEEARRKAEEEERK 97

EQREKEAEDLEQLRLKREQRKQERIEEDRRLLEIRKEEDKRRKAEEEERK 92 EOREKEADDLEOLROKRESRKOERIEEDRRLLEVRKEEDKRRKREEEERK 98 KRMEKDLLELQTLIDVHFEQRKKEEEE----LVALKERIERRRSERAEQQ 114 KRQNKDLMELQALIDSHFEARKKEEEE----LIALKERIEKRRAERAEQQ 97 KRVEKDFNELQSLINLHFTTRQKEEDE----LVALKNRIERRRTDRADQQ 146 KRQNKDLVELOGLIDAHFEHRKKEEEE----LISLKERIEKRRAERAEON 78

RKKAEEERKRKEERERKRREQEEMIKNMRKPNFVISKREGDPKGGGETNG 147 RKKQEDERKRIEAKKAKLKELEERKKMSKTPNFVITKK-------GASN- 134 RKKQEEERKRIEAKKIKLKEMEERKKMSKTPNFVITKK-------GASN- 140 RERTEKEREROAKLAEEKMRKEEEEAKKRAEDDAKKKK----VLSNMGAH 160 RIRAEKERERONRLAEEKARREEEDAKRRAEDDMKKKK----ALSSMGAN 143 RIRTERDRERQARLAEERARREEEAAKLRAEEDARKKK----ILSNKG-- 190 RIRSEKEKERAARREEERLKREEADAKKKADEDAKKKS----ALSSMGSN 124

PIEOVEDGEKEVOKSKEOLEAEKRAILAORIKPLTTDGLDTAKLVEMAKE 197 - - LEFASKDMAKSKEOLEEEKRAIIAORIOPLTVDGLDLAALMEKATE 180 ----LEEASKDMAKSKEQLEEEKRAILAQRIQPLSVDGLDLASLMEKATE 186 FGGYLVKAEQKRG-KRQTGREMKVRILSERKKPLDIDYMGEEQLREKAQE 209 YSSYLAKADQKRG-KKQTAREMKKKI LAERRKPLNIDHLSDDKLRDKAKE 192 YGGFLOKVDOKKG-KKLTEREKKTKCLLERRKPLNIDHLNOEKLGEKALD 239 YSSHLQKADSKRGGKKETEREKKKKILASRRKVLN I DHLNEEKLKEKAKE 174

LHQNIFRLMNEKYDMEEKFKRQQYDMIELAERARQMNKGKSRRGEARVDE 247 FHNKIKSLANEKYELEERFKSOOYDMIELAERAROMNKGKKR--AVOVDD 228 FHNKIKNLANEKYELEERFKSQQYDMIELAERARQMNKGKKR--AVQVDD 234 LSDWI HQLESEKFDLMAKLKOOKYEINVLYNRISHAOKFRKGAGKGRVGG 259 LWDTLYQLETDKFEFGEKLKRQKYDITTLRSRIDQAQKHSKKAGATAKGK 242 LWKWLNQLHAEKFELGEKLKSQKYEIKVLRNRVSDHQKGTKVAKTTRKSW 289 LHEWMQTLESEKFDNMERLKRQKYEVTTLRKRVEELSKFSKK-GKTVRRK 223 (28\%)

SFDRLADKFAGAPPKIOLCSKYERHTDHRSYDORKDIYEELSKPIE-PPK 296 SYDPMAEKYGSCPPKVQMYSKYERHTDLRTYGTRVDYFETKAKKIEAEMA 278 SFDPLAEKYTSAPPKVQMYSKYERHTDLRTYGTRVDYFETKAKKIEAELA 284

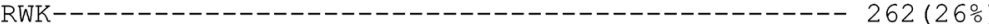

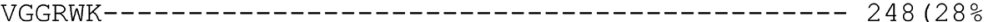
K-------------------------------------------- 290 (19\%) IGRRODEE------------GEAA---------EAEEGGEE- 316 IGRKKEEDNLLKTMEETEETSEAA------PAPEAEVAAEEE 314 (51\%) IG-KKDEDILLETMEQSEENPEAAPEAAPEPAPETEVAAEEE 325 (52\%)

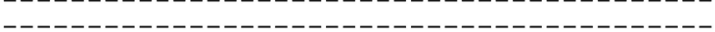

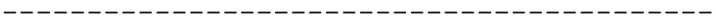

Figure 2. Multiple sequence alignments of the Pinctada fucata troponin T amino acid sequence determined in this study to troponin T proteins from other species. Sequences for comparison were obtained from the DNA Data Bank of Japan database: Japanese scallop, Chlamys nipponensis (D88423), Yesso scallop Mizuhopecten yessoensis (AB004637), human Homo sapiens (S69208), mouse Mus musculus (L49018), zebrafish Danio rerio (AF512524) and Atlantic salmon Salmo salar (AF072687). Numbers on the right represent the number of amino acid residues from the $\mathrm{N}$-terminus. Gaps were inserted to optimize the sequence alignments. Homologies between Pifuc- $\operatorname{Tn} \mathrm{T}$ and the comparison sequences are represented in parentheses.

a sequence of nine residues (ETNGPIEQV; 144 - 152) from our obtained Pifuc-TnT protein sequence. BLAST searching against the protein database UniProt yielded an exact-match sequence of putative $P$. fucata TnT (accession number A0A194AM07). These results demonstrate our definitive determination 
of the nucleotide and protein sequences of Pifuc-TnT.

\subsection{Gene Structure of $P$. fucata TnT}

BLAST searching of our obtained Pifuc-TnT nucleotide sequence against the genome database of $P$. fucata yielded a single nucleotide sequence at scaffold 648.1. We then predicted the gene structure of Pifuc-TnT using Splign alignment of the obtained cDNA and genome sequences [27]. Pifuc-TnT consists of 13 exons (Figure 3), with start and stop codons located in exon 2 and exon 12, respectively.

\subsection{Distribution of TnT mRNA in P. fucata Tissues}

Pifuc-TnT mRNA was predominantly expressed in adductor phasic muscle, with weak expression detected in adductor catch muscle, slight expression detected in the gill, and no detectable expression in the mantle and foot (Figure 4). Therefore, the tissue distribution of Pifuc-TnT mRNA is equivalent to that of Pifuc-TnC and Pifuc-TnI [14] [15]. These findings suggest that instead of the catch adductor muscle, Tn is involved in regulating the adductor phasic muscle contraction.

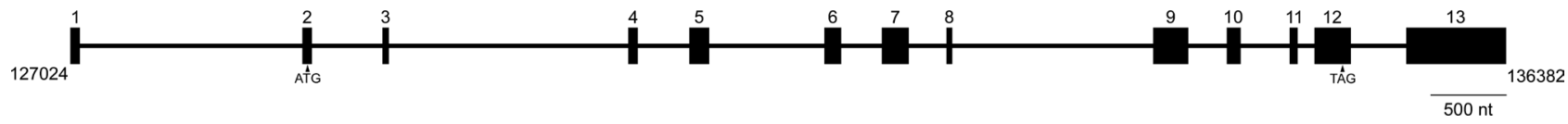

Figure 3. Pinctada fucata troponin T gene structure. Black boxes indicate exons, and intervening lines represent introns. ATG and TAG indicate the start and stop codons, respectively.

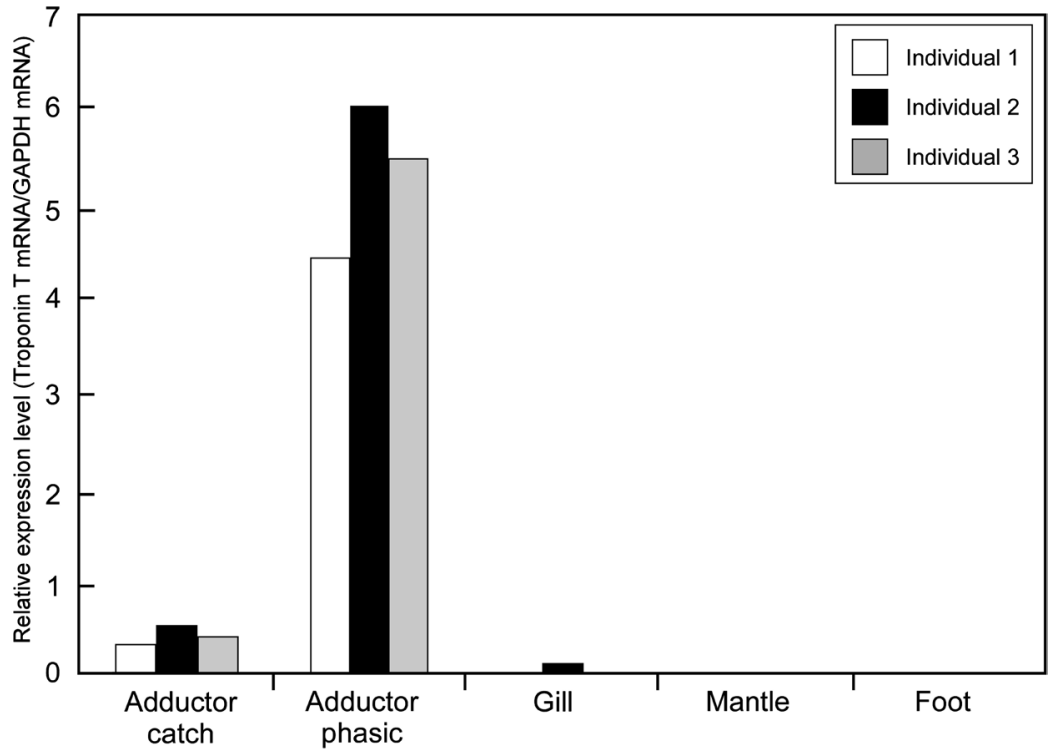

Figure 4. Troponin T gene expression patterns in Pinctada fucata tissues. Quantitative real-time PCR analysis was performed to examine troponin T mRNA expression in $P$. fucata adductor catch muscle, adductor phasic muscle, gill, mantle and foot. The data shown are representative of three independent experiments. The y-axis indicates relative troponin T expression levels using GAPDH as an internal standard. 


\subsection{Interaction of TnT with Tropomyosin Isoforms of $P$. fucata}

Unexpectedly, ITC analysis did not show interaction between Pifuc-TnT and Pifuc-TM1 or Pifuc-TM2 under the conditions of this study (Figure 5).

\section{Discussion}

In this study, we have added the molecular characterization of Pifuc-TnT to our previous studies of Pifuc-TnC and Pifuc-TnI [14] [15], completing the subunit characterization of Pifuc-Tn. As shown in Figure 4, like the genes encoding the other subunits, Pifuc-TnT was mainly expressed in adductor phasic muscle. These findings strongly indicated that Pifuc-Tn plays a role in the regulatory system of adductor phasic muscle contraction. Our previous study showed that Pifuc-TnC, which has one $\mathrm{Ca}^{2+}$ binding site at the EF-hand motif site IV, induces conformational change by binding $\mathrm{Ca}^{2+}[13]$. The conformational change in $\mathrm{TnC}$ in vertebrate skeletal muscle causes the conformational change in Tn, releasing an inhibition of the interaction between the filaments of myosin and actin. Although there are some differences in the primary structures of TnI and TnT between $P$. fucata and vertebrates, they might behave similarly. Analogous to known

(a)

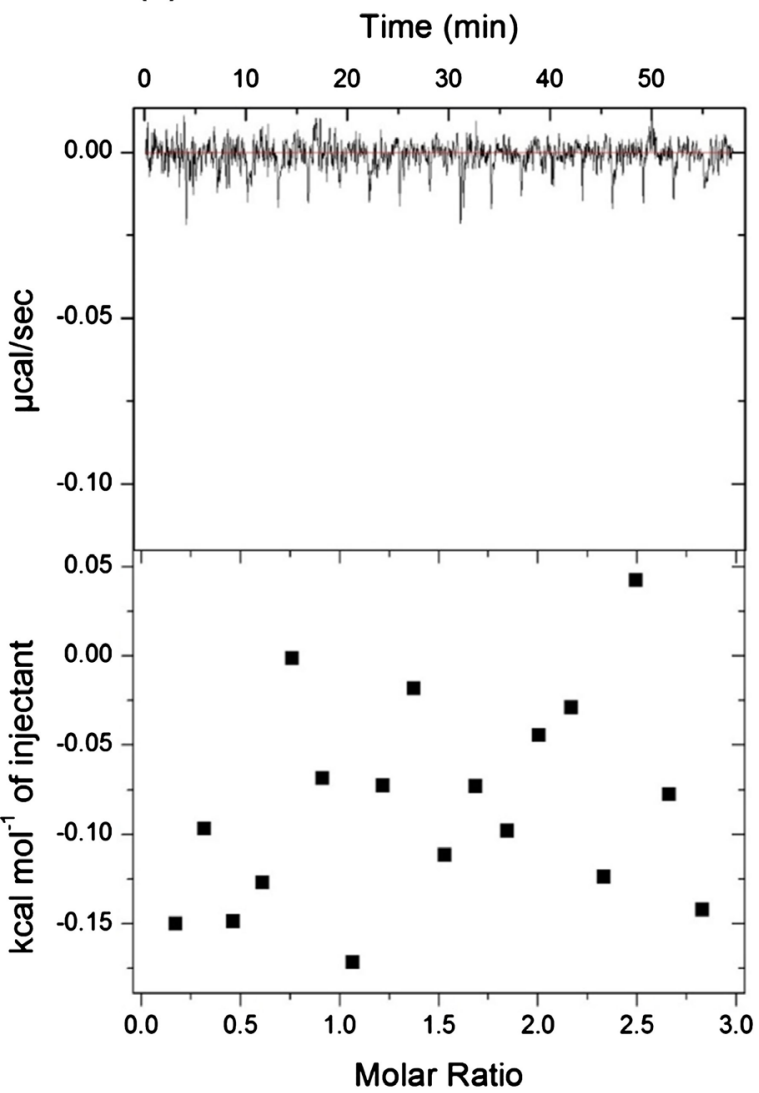

(b)

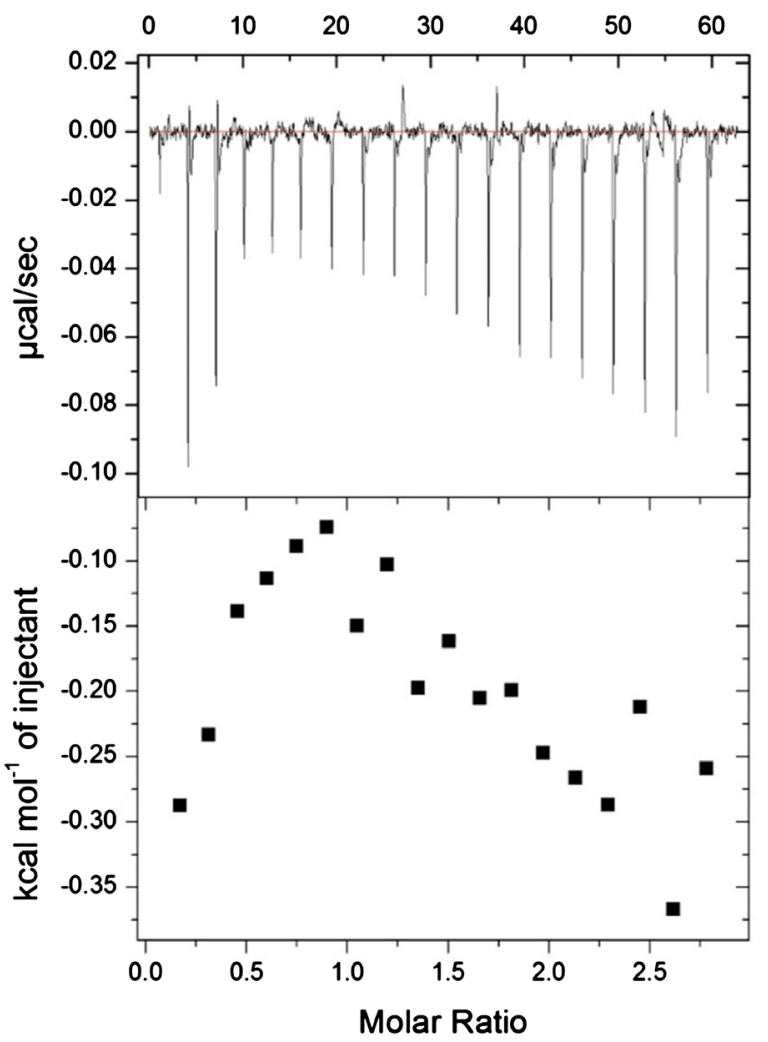

Figure 5. Isothermal titration calorimetric analysis of Pifuc-TnT to Pifuc-TM1 and Pifuc-TM2. Titration curve of interactions between Pifuc-TnT and Pifuc-TM1 (a), and Pifuc-TnT and Pifuc-TM2 (b). In each case, the upper panel shows raw energy changes during the titration (time), while the lower panel presents the derived integrated total energy changes as a function of the molar ratio of the interactants. 
scallop TnIs, Pifuc-TnI has an N-terminal sequence extension of 136 residues that rabbit skeletal TnI does not have [19] [20]. Pifuc-TnT, as revealed in this study, has a C-terminal sequence extension of more than 60 residues that is not seen in vertebrate $\mathrm{TnT}$ proteins. These distinct features raise the possibility that Pifuc-Tn might operate differently from vertebrate skeletal muscle Tn with regard to the regulation of adductor phasic muscle.

Initially we predicted that Pifuc-TnT would interact with either Pifuc-TM1 or Pifuc-TM2, or both. However, unexpectedly, as revealed by the ITC analysis shown in Figure 5, we were unable to detect such an interaction. There is no obvious explanation for a lack of interaction between these proteins. We used bacterially expressed Pifuc-TnT and Pifuc-TMs in the assay; thus it is possible that the proteins were improperly folded during purification from $E$. coli. Alternatively, Pifuc-TnT might not interact with Pifuc-TM in isolation; that is, the interaction might require formation of the complex of Pifuc-TnT, Pifuc-TnI and Pifuc-TnC. We plan to repeat the binding assay using the Tn complex in our next study.

In mammals, there is muscle type-specific expression of $\mathrm{TnT}$ isoforms in cardiac, slow and fast skeletal muscles [30]. Expression of the three TnT isoform genes in adult cardiac and skeletal muscles is strictly controlled in a muscle fiber type-specific manner. In this study, we identified only one Pifuc-TnT transcript by cDNA cloning (Figure 1). The results of BLAST searching using the Pifuc-TnT sequence against the genome database indicate that there is likely only one TnT gene in the P. fucata genome. Each of the three mammalian TnT isoform genes generate additional multiple protein isoforms by alternative RNA splicing [30]. In contrast, we found no splicing variants of Pifuc-TnT by cDNA cloning using the RNA from phasic adductor muscle from 2-year-old P. fucata. However, it is possible that Pifuc-TnT produces isoforms by alternative RNA splicing that are dependent on the developing stage of $P$. fucata. Further study is needed to reveal potential Pifuc-TnT isoforms.

In summary, our group has now described the molecular characteristics of all of the key proteins thought to be involved in the thin filament-linked regulatory system of P. fucata: troponin C [14], troponin I [15], troponin T (this study), tropomyosin-1 and -2 [24], and calponin-1, $-2,-3,-4,-5,-6$ and -7 [31]. Calponin, a thin filament-associated protein, is considered to be involved in vertebrate smooth muscle contraction. Therefore, calponin is another candidate regulator of molluscan muscle contraction, although its function in molluscan muscle is unknown. Using this information, we plan to perform experiments to elucidate the thin filament-linked regulatory system of molluscan muscles.

\section{Acknowledgements}

This study was supported by JSPS KAKENHI Grant Number JP16K07872. We thank Michelle Kahmeyer-Gabbe, PhD, from Edanz Group

(http://www.edanz.com/ac) for editing a draft of this manuscript. 


\section{Conflicts of Interest}

The authors declare no conflicts of interest regarding the publication of this paper.

\section{References}

[1] Funabara, D., Kanoh, S., Siegman, M.J., Butler, T.M., Hartshorne, D.J. and Watabe, S. (2005) Twitchin as a Regulator of Catch Contraction in Molluscan Smooth Muscle. Journal of Muscle Research and Cell Motility, 26, 455-460. https://doi.org/10.1007/s10974-005-9029-2

[2] Funabara, D., Hamamoto, C., Yamamoto, K., Inoue, A., Ueda, M., Osawa, R., Kanoh, S., Hartshorne, D.J., Suzuki, S. and Watabe, S. (2007) Unphosphorylated Twitchin Forms a Complex with Actin and Myosin That May Contribute to Tension Maintenance in Catch. Journal of Experimental Biology, 210, 4399-4410. https://doi.org/10.1242/jeb.008722

[3] Funabara, D., Osawa, R., Ueda, M., Kanoh, S., Hartshorne, D.J. and Watabe, S. (2009) Myosin Loop 2 Is Involved in the Formation of a Trimeric Complex of Twitchin, Actin, and Myosin. The Journal of Biological Chemistry, 284, 18015-18020. https://doi.org/10.1074/jbc.M109.016485

[4] Butler, T.M., Mooers, S.U., Narayan, S.R. and Siegman, M.J. (2010) The N-Terminal Region of Twitchin Binds Thick and Thin Contractile Filaments: Redundant Mechanisms of Catch Force Maintenance. The Journal of Biological Chemistry, 285, 40654-40665. https://doi.org/10.1074/jbc.M110.166041

[5] Leavis, P.C., Gergely, J. and Szent-Gyorgyi, A.G. (1984) Thin Filament Proteins and Thin Filament-Linked Regulation of Vertebrate Muscle Contraction. Critical Reviews in Biochemistry, 16, 235-305. https://doi.org/10.3109/10409238409108717

[6] Ohtsuki, I., Maruyama, K. and Ebashi, S. (1986) Regulatory and Cytoskeletal Proteins of Vertebrate Skeletal Muscle. Advances in Protein Chemistry, 38, 1-67. https://doi.org/10.1016/S0065-3233(08)60525-2

[7] Zot, A.S. and Potter, J.D. (1987) Structural Aspects of Troponin-Tropomyosin Regulation of Skeletal Muscle Contraction. Annual Review of Biophysics and Biophysical Chemistry, 16, 535-559. https://doi.org/10.1146/annurev.bb.16.060187.002535

[8] Farah, C.S. and Reinach, F.C. (1995) The Troponin Complex and Regulation of Muscle Contraction. FASEB Journal, 9, 755-767.

https://doi.org/10.1096/fasebj.9.9.7601340

[9] Nagai, K. (2013) A History of the Cultured Pearl Industry. Zoological Science, 30, 783-793. https://doi.org/10.2108/zsj.30.783

[10] Takeuchi, T., Kawashima, T., Koyanagi, R., Gyoja, F., Tanaka, M., Ikuta, T., Shoguchi, E., Fujiwara, M., Shinzato, C., Hisata, K., Fujie, M., Usami, T., Nagai, K., Maeyama, K., Okamoto, K., Aoki, H., Ishikawa, T., Masaoka, T., Fujiwara, A., Endo, K., Endo, H., Nagasawa, H., Kinoshita, S., Asakawa, S., Watabe, S. and Satoh, N. (2012) Draft Genome of the Pearl Oyster Pinctada fucata: A Platform for Understanding Bivalve Biology. DNA Research, 19, 117-130. https://doi.org/10.1093/dnares/dss005

[11] Funabara, D., Watanabe, D., Satoh, N. and Kanoh, S. (2013) Genome-Wide Survey of Genes Encoding Muscle Proteins in the Pearl Oyster, Pinctada fucata. Zoological Science, 30, 817-825. https://doi.org/10.2108/zsj.30.817

[12] Takeuchi, T., Koyanagi, R., Gyoja, F., Kanda, M., Hisata, K., Fujie, M., Goto, H., Yamasaki, S., Nagai, K., Morino, Y., Miyamoto, H., Endo, K., Endo, H., Nagasawa, H., Kinoshita, S., Asakawa, S., Watabe, S., Satoh, N. and Kawashima, T. (2016) Bi- 
valve-Specific Gene Expansion in the Pearl Oyster Genome: Implications of Adaptation to a Sessile Lifestyle. Zoological Letters, $2,3$.

https://doi.org/10.1186/s40851-016-0039-2

[13] Funabara, D., Ishikawa, D., Urakawa, Y. and Kanoh, S. (2018) $\mathrm{Ca}^{2+}$-Induced Conformational Change of Troponin C from the Japanese Pearl Oyster, Pinctada fucata. American Journal of Molecular Biology, 8, 205-214. https://doi.org/10.4236/ajmb.2018.84018

[14] Funabara, D., Urakawa, Y. and Kanoh, S. (2018) Molecular Cloning and Tissue Distribution of Troponin C from the Japanese Pearl Oyster, Pinctada fucata. American Journal of Molecular Biology, 8, 166-177. https://doi.org/10.4236/ajmb.2018.83014

[15] Funabara, D., Urakawa, Y. and Kanoh, S. (2019) Molecular Cloning and Tissue Distribution of Troponin I from the Japanese Pearl Oyster, Pinctada fucata. American Journal of Molecular Biology, 9, 29-40. https://doi.org/10.4236/ajmb.2019.92003

[16] Nishita, K., Tanaka, H. and Ojima, T. (1994) Amino Acid Sequence of Troponin C from Scallop Striated Adductor Muscle. Journal of Biological Chemistry, 269, 3464-3468.

[17] Ojima, T., Tanaka, H. and Nishita, K. (1994) Cloning and Sequence of a cDNA Encoding Akazara Scallop Troponin C. Archives of Biochemistry and Biophysics, 311 , 272-276. https://doi.org/10.1006/abbi.1994.1237

[18] Ojima, T., Ohta, T. and Nishita, K. (2001) Amino Acid Sequence of Squid Troponin C. Comparative Biochemistry and Physiology Part B, 129, 787-796. https://doi.org/10.1016/S1096-4959(01)00397-9

[19] Tanaka, H., Ojima, T. and Nishita, K. (1998) Amino Acid Sequence of Troponin-I from Akazara Scallop Striated Adductor Muscle. Journal of Biochemistry, 124, 304-310. https://doi.org/10.1093/oxfordjournals.jbchem.a022112

[20] Tanaka, H., Takeya, Y., Doi, T., Yumoto, F., Tanokura, M., Ohtsuki, I., Nishita, K. and Ojima, T. (2005) Comparative Studies on the Functional Roles of N- and C-Terminal Regions of Molluskan and Vertebrate Troponin-I. The FEBS Journal, 272, 4475-4486. https://doi.org/10.1111/j.1742-4658.2005.04866.x

[21] Layland, J., Solaro, R.J. and Shah, A.M. (2005) Regulation of Cardiac Contractile Function by Troponin I Phosphorylation. Cardiovascular Research, 66, 12-21. https://doi.org/10.1016/j.cardiores.2004.12.022

[22] Perry, S.V. (1998) Troponin T: Genetics, Properties and Function. Journal of Muscle Research and Cell Motility, 19, 575-602. https://doi.org/10.1023/A:1005397501968

[23] Pearlstone, J.R., Carpenter, M.R., Johnson, P. and Smillie, L.B. (1976) Amino-Acid Sequence of Tropomyosin-Binding Component of Rabbit Skeletal Muscle Troponin. Proceedings of the National Academy of Sciences of the United States of America, 73, 1902-1906. https://doi.org/10.1073/pnas.73.6.1902

[24] Funabara, D., Ohta, A., Sueyoshi, J. and Kanoh, S. (2019) Tropomyosin Isoform Expression in the Adductor Muscle of the Japanese Pearl Oyster, Pinctada fucata. American Journal of Molecular Biology, 9, 16-27. https://doi.org/10.4236/ajmb.2019.91002

[25] Chomczynski, P. (1993) A Reagent for the Single-Step Simultaneous Isolation of RNA, DNA and Proteins from Cell and Tissue Samples. BioTechniques, 15, 532-537.

[26] Larkin, M.A., Blackshields, G., Brown, N.P., Chenna, R., McGettigan, P.A., McWilliam, H., Valentin, F., Wallace, I.M., Wilm, A., Lopez, R., Thompson, J.D., Gibson, T.J. and Higgins, D.G. (2007) Clustal W and Clustal X Version 2.0. Bioinformatics, 
23, 2947-2948. https://doi.org/10.1093/bioinformatics/btm404

[27] Kapustin, Y., Souvorov, A., Tatusova, T. and Lipman, D. (2008) Splign: Algorithms for Computing Spliced Alignments with Identification of Paralogs. Biology Direct, 3, 20. https://doi.org/10.1186/1745-6150-3-20

[28] Studier, F.W. (2005) Protein Production by Auto-Induction in High-Density Shaking Cultures. Protein Expression and Purification, 41, 207-234.

https://doi.org/10.1016/j.pep.2005.01.016

[29] Inoue, A., Ojima, T. and Nishita, K. (1996) Cloning and Sequencing of a cDNA for Akazara Scallop Troponin T. Journal of Biochemistry, 120, 834-837.

https://doi.org/10.1093/oxfordjournals.jbchem.a021487

[30] Wei, B. and Jin, J.-P. (2011) Troponin T Isoforms and Posttranscriptional Modifications: Evolution, Regulation and Function. Archives of Biochemistry and Biophysics, 505, 144-154. https://doi.org/10.1016/j.abb.2010.10.013

[31] Funabara, D., Osakabe, Y. and Kanoh, S. (2019) Calponin Isoform Expression in the Japanese Pearl Oyster, Pinctada fucata. American Journal of Molecular Biology, 9 , 154-172. https://doi.org/10.4236/ajmb.2019.94012 